\title{
Evaluation of the palatal split pattern in surgically rapid maxillary expansion - comparison of two techniques
}

\author{
Lucas Borin Moura ${ }^{1} \cdot$ Rubens Spin-Neto $^{2} \cdot$ Cássio Edvard Sverzut $^{3}$. \\ Marcelo da Silva Monnazzi ${ }^{1}$ • Alexandre Elias Trivellato ${ }^{3}$. \\ Marisa Aparecida Cabrini Gabrielli ${ }^{1}$ - Valfrido Antonio Pereira-Filho ${ }^{1}$
}

Received: 14 January 2016 / Accepted: 2 May 2016 / Published online: 7 May 2016

(C) Springer-Verlag Berlin Heidelberg 2016

\begin{abstract}
Purpose Surgically assisted rapid maxillary expansion is performed to correct transverse deficiencies of the maxilla, and it is indicated in specific clinical situations. The literature presents different opinions in several aspects, mainly regarding the effect of disjunction of the pterygoid plates. The aim of this study was to evaluate the pattern of maxillary expansion obtained with two surgical techniques, with and without disjunction of the pterygoid plates.Methods Twenty patients treated with surgically assisted rapid maxillary expansion for correction of transversal discrepancies were included in this retrospective study and divided into two groups: (G1) patients operated without disjunction of pterygoid plates and $(\mathrm{G} 2)$ patients treated with release of the pterygoid plates.

Results There were seven male and 13 female patients, and the mean age was 29.9 years. Cone beam computed tomography images obtained after final activation of the expansion device were evaluated and complete disjunction of the midpalatal suture (type I) was present in $75 \%$ of the patients whereas incomplete disjunction of the midpalatal suture (type II) was observed in $25 \%$. Chi-square test showed no statistically significant difference between groups $(p=0.606)$.
\end{abstract}

Lucas Borin Moura

lucasbmoura@gmail.com

1 Division of Oral and Maxillofacial Surgery, Department of Diagnosis and Surgery, Dental School at Araraquara - Unesp, Rua: Humaitá, 1680, Araraquara, SP 14801-903, Brazil

2 Section of Oral Radiology, Department of Dentistry, Faculty of Health, Aarhus University, Aarhus, Denmark

3 Department of Oral and Maxillofacial Surgery and Periodonthology, Dental School at Ribeirão Preto-USP, Ribeirão Preto, SP, Brazil
Conclusion No difference was found in relation to the maxillary disjunction pattern irrespective of the treatment given to pterygoid plates.

Keywords Palatal expansion technique $\cdot$ LeFort I osteotomy · Maxilla $\cdot$ Cranial sutures $\cdot$ SARME

\section{Introduction}

Almost $30 \%$ of adult orthodontic patients present transverse maxillary deficiency [1]. The modern orthodontic treatment is successful to correct this deficiency in children up 15 years, depending on gender, but it is inefficient when ossification of the midpalatal suture occurs [2]. Surgically assisted rapid maxillary expansion (SARME) is indicated to patients who already achieved maturity of the suture and must reach a maxillary expansion greater than $5 \mathrm{~mm}[3,4]$.

The SARME technique proposed by Bell and Jacobs [5] consists in osteotomies of the zygomaticomaxillary buttress and the midpalatal suture, in order to weaken those structures and allow the maxillary expansion to proceed by activation of the orthodontic expansion device. The release of the pterygoid plates should be realized when expansion greater than $7 \mathrm{~mm}$ is required $[6,7]$.

Even so, the technique is controversial in relation to the real benefits of releasing (+LPP) or not (-LPP) the lateral pterygoid plates and possibility of complications due to lesion of anatomical structures in that region [7-9]. The current discussion is about the pattern of maxillary expansion. Several authors report that the uniform and complete palatal split (anterior to posterior) is more likely to happen when the SARME + LPP is performed $[3,6]$. However, there are some studies that deny 
those conclusions and state that the same type of expansion is obtained with both techniques [10,11].

Pereira et al. [12] published a study that evaluated the palatal bone split using computed tomography to classify the bone split as complete or incomplete (up to the palatine bone). The present study aims to use this classification method to compare the maxillary expansion techniques with (+LPP) or without (-LPP) release of pterygoid plates and verify if the separation of the pterygoid plates makes a difference in the palatal bone split.

\section{Material and method}

A retrospective analysis was performed on the database of patients submitted to SARME in descending chronological order. To be included in the sample, medical records of patients with transverse maxillary deficiency greater than $7 \mathrm{~mm}$ were selected. Cone beam computed tomography (CBCT) scans obtained preoperatively and after completion of the activation of the expansion device had to be available. Syndromic patients, those presenting orofacial clefs, patients who underwent previous maxillary surgery, or who had medical records without CBCT were excluded.

The subjects were divided into two groups according to the surgical technique applied: (G1) SARME without the disjunction of pterygoid plates (-LPP) and (G2) SARME with disjunction of pterygoid plates (+LPP). All patients were operated by trained oral and maxillofacial surgeons.

In G1, the surgical technique was performed just as described by Bell and Jacobs [5]. In G2, the procedure included the disjunction of the pterygoid plates using a curved chisel as described by Betts et al. [13]. Both groups had the same postoperative expansion protocol. The distraction device used was the Hyrax (Dentaurum, 802-602) anchored to the first premolars and the first molars by orthodontic bands. The activation was initiated in the 7th postoperative day and was performed by the patient under professional supervision. The activation followed the pattern of one quarter of turn three times per day, totalizing $0.75 \mathrm{~mm}$ daily. After the activation period, when the desired expansion was achieved, the distractor was locked for osseous consolidation for at least 4 months.

The postoperative $\mathrm{CBCT}$ scan obtained after completion of the activation was evaluated by a single calibrated blinded individual with the Osirix ${ }^{\circledR}$ software used to classify the palatal bone split pattern according to Pereira et al. [12], as follows:

- Type I: Complete disjunction of midpalatal suture from the anterior nasal spine to the posterior nasal spine (Fig. 1);

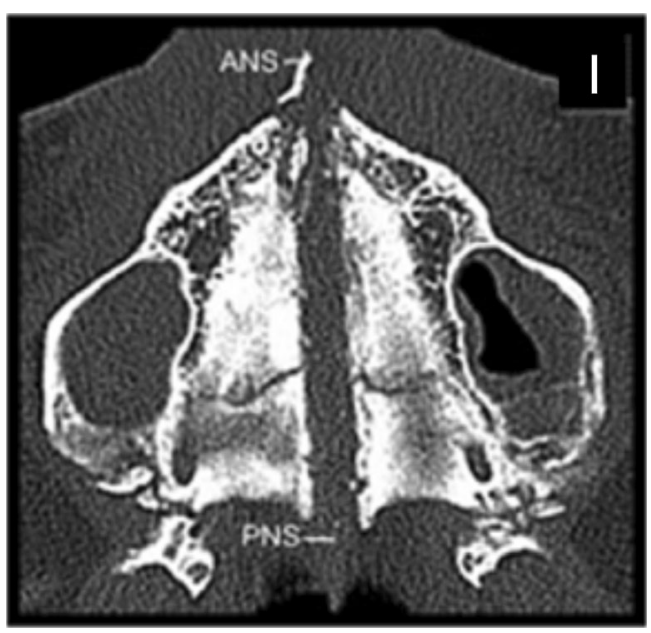

Fig. 1 Type I palatal split pattern: Complete disjunction of the midpalatal suture from the anterior nasal spine to the posterior nasal spine. ANS anterior nasal spine, $P N S$ posterior nasal spine

- Type II: Incomplete disjunction of the midpalatal suture, from the anterior nasal spine to the transverse palatal suture, with small or no posterior split and thus not including the palatine bone (Fig. 2).

The association of the surgical technique with the palatal bone split pattern was evaluated by the chi-square test $(p<0.05)$.

\section{Results}

The study included 20 patients submitted to SARME, 13 females and seven males, with a mean age of 29.9 years. Group I included three male and seven female patients, mean age of 30.6 years, and Group II had four male and six female

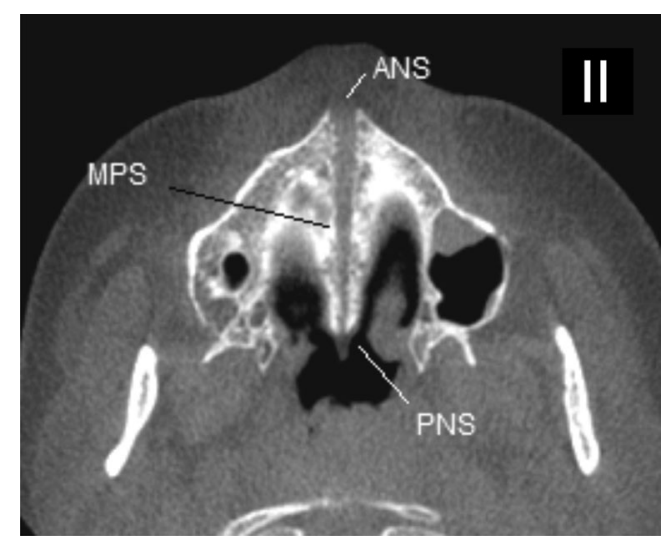

Fig. 2 Type II palatal split pattern: Incomplete disjunction of the midpalatal suture, from the anterior nasal spine to the transverse palatal suture, with small or no posterior split and thus not including the palatine bone. ANS anterior nasal spine, MPS midpalatal suture, PNS posterior nasal spine 
patients, mean age of 29.3 years. The mean of bone expansion in anterior nasal spine area was $5.75 \pm 1.44 \mathrm{~mm}$ in G1 and $5.61 \pm 1.51 \mathrm{~mm}$ in $\mathrm{G} 2$. The center area of palate was $3.31 \pm 1.27 \mathrm{~mm}$ in $\mathrm{G} 1$ and $3.03 \pm 1.48 \mathrm{~mm}$ in $\mathrm{G} 2$.

According to the CBCT scan images, $75 \%$ of the individuals had palatal type I split pattern and $25 \%$ presented the type II, considering both groups together. Viewing G1 and G2 separately, a higher prevalence of type I split pattern was found in G1, in which the disjunction of pterygoid plates was not performed (Table 1).

The analysis of the palatal split pattern through the chi-square test did not show statistic significant difference between the groups $(p=0.606)$. The direct comparison between groups resulted in tendency for both to the type I palatal split pattern.

\section{Discussion}

Although SARME is a widely employed procedure for treatment of transverse maxillary deficiency, it still divides authors in several aspects. Some believe that the separation of the pterygoid plates is of great matter to obtain a homogeneous maxillary bone split and others believe that it does not change the split pattern.

The palatine suture was considered the most important one when the orthopedic maxillary expansion techniques were created, but nowadays, the role of the pterygopalatine, nasomaxillary, frontomaxillay, zygomaticmaxillary, frontonasal, frontalzygomatic sutures, and the cranial base is clear [11, 14-17]. Although there is no consensus about the effectiveness of pterygoid plate separation, some studies show the important role of the lateral wall of the maxilla, palatine suture, and pterygopalatine suture in the distribution of load to the facial skeleton and skull base during the SARME activation period $[18,19]$.

Holberg et al. [20] using finite elements analysis to evaluate midfacial and cranial stress distribution in SARME+LPP and SARME-LPP considered that the disjunction of pterygoid plates is a reasonable and necessary additional measure to protect the cranial base from undesirable side effects, such as high and concentrated stress.

Table 1 Distribution of palatal split pattern according to surgical technique

\begin{tabular}{llll}
\hline Group & \multicolumn{2}{l}{ Palatal split pattern } & \multirow{2}{*}{ Total } \\
\cline { 2 - 3 } & Type I & Type II & \\
\hline G1 & 8 & 2 & 10 \\
G2 & 7 & 3 & 10 \\
Total & 15 & 5 & 20 \\
\hline
\end{tabular}

Some authors consider that the more conservative approach (-LPP), which removes the resistance from the zygomaticomaxillary buttress, is enough for adequate maxillary expansion [11, 21-23]. However, several authors associate the SARME-LPP technique with complications such as augmented pain during the activation period, relapse, lesser amount of expansion, and torque effect over teeth. The high stress created in cranial base due to the -LPP technique can result in rare but major complications, such as blindness or ophthalmoplegia, as a result of optic or abducens nerve injury $[3,9,24,25]$.

Racey [26] reports that the +LPP technique is rarely necessary to obtain maxillary expansion, but when not performed, the result tends to be a "V" pattern of expansion, with a greater opening in the anterior maxilla and less expansion in the posterior area. In the present study, that did not happen. Both SARME techniques showed similar pattern of expansion.

Pereira et al. [12] used a new method of classification to study the palatal split pattern in two different groups of patient, G1 that used the Hass distractor and G2 that used the Hyrax distractor, both submitted by SARME+LPP technique. Their result showed global prevalence of partial maxillary expansion (type II). These results are in opposite to those obtained in the present study where the type I of pattern was more prevalent in both groups.

In the present study, there were no statistical differences between the groups, so the palatal split pattern was not modified by the separation of the pterygoid plates. The most prevalent palatal split pattern was the type I, where the disjunction was complete, from anterior to posterior nasal spine. However, being a retrospective study of a relatively small sample size, randomized clinical trials are necessary to further study the matter.

\section{Compliance with ethical standards}

Conflict of interest The authors declare that they have no conflicts of interest.

\section{References}

1. Proffit WR, Phillips C, Dann C 4th (1990) Who seeks surgical-orthodontic treatment? Int J Adult Orthodon Orthognath Surg 5:153-180

2. Bishara SE, Staley RN (1987) Maxillary expansion: clinical implications. Am J Orthod Dentofac Orthop 91:3-14

3. Koudstaal MJ, Poort LJ, van der Wal KG, Wolvius EB, PrahlAndersen B, Schulten AJ (2005) Surgically assisted rapid maxillary expansion (SARME): a review of the literature. Int J Oral Maxillofac Surg 34:709-714

4. Altug Atac AT, Karasu HA, Aytac D (2006) Surgically rapid maxillary expansion compared with orthopedic rapid maxillary expansion. Angle Orthod 76:353-359

5. Bell WH, Jacobs JD (1979) Surgical-orthodontic correction of horizontal maxillary deficiency. J Oral Surg 37:897-902 
6. Matteini C, Mommaerts MY (2001) Posterior transpalatal distraction with pterygoid disjunction: a short-term model study. Am J Orthod Dentofac Orthop 120:498-502

7. Robiony M, Polini F, Costa F, Zerman N, Politi M (2007) Ultrasonic bone cutting for surgically assisted rapid maxillary expansion (SARME) under local anaesthesia. Int J Oral Maxillofac Surg 36:267-269

8. Mehra P, Cottrell DA, Caiazzo A, Lincoln R (1999) Life-threatening, delayed epistaxis after surgically assisted rapid palatal expansion: a case report. J Oral Maxillofac Surg 57:201-204

9. do Egito Vasconcelos BC, Caubi AF, Dias E, Lago CA, Porto GG (2006) Surgically assisted rapid maxillary expasion: a preliminar study. Braz J Otorhinolaryngol 72:457-461.

10. Pogrel MA, Kaban LB, Vargervik K, Baumrind S (1992) Surgically assisted rapid maxillary expansion in adults. Int $\mathrm{J}$ Adult Orthodon Orthognath Surg 7:37-41

11. Nothway WM, Meade JB Jr (1997) Surgically assisted rapid maxillary expansion: a comparison of technique, response, and stability. Angle Orthod 67:309-320

12. Pereira MD, Prado GP, Abramoff MM, Aloise AC, Masko Ferreira L (2010) Classification of midpalatal suture opening after surgically assisted rapid maxillary expansion using computer tomography. Oral Surg Oral Med Oral Pathol Oral Radiol Endod 110:41-45. doi:10.1016/j.tripleo.2009.12.028

13. Betts NJ, Vanarsdall RL, Barber HD, Higgins-Barber K, Fonseca RJ (1995) Diagnosis and treatment of transverse maxillary deficiency. Int J Adult Orthodon Orthognath Surg 10:75-96

14. Sygouros A, Motro M, Ugurlu F, Acar A (2014) Surgically assisted rapid maxillary expansion: cone-beam computed tomography evaluation of different surgical techniques and their effects on the maxillary dentoskeletal complex. Am J Orthod Dentofac Orthop 146: 748-757. doi:10.1016/j.ajodo.2014.08.013

15. Kokich VG (1992) Sutural response to orthopedic forces. In: Carson DS, Goldstein SA (eds) Bone biodynamics in orthodontic and orthopedic treatment, 1st edn. Michigan, Ann Arbor, pp. 173188

16. Remmelink HJ (1988) Orientation of maxillary sutural surfaces. Eur J Orthod 10:233-236

17. Wagemans PA, van de Velde JP, Kujipers-Jagtman AM (1988) Sutures and forces: a review. Am J Orthod Dentofacil Orthop 94: 129-141

18. Kraut RA (1984) Surgically assisted rapid maxillary expansion by opening the midpalatal suture. J Oral Maxillofac Surg 42:651-655

19. Glassman AS, Nahigian SJ, Medway JM, Aronowitz HI (1984) Conservative surgical orthodontic adult rapid palatal expansion: sixteen cases. Am J Orthod 86:207-213

20. Holberg C, Steinhauser S, Rudzki I (2007) Surgically assisted rapid maxillary expansion: midfacial and cranial stress distribution. Am J Orthod Dentofac Orthop 132:776-782

21. Bays RA, Greco JM (1992) Surgically assisted rapid palatal expansion: an outpatient technique with long-term stability. J Oral Maxillofac Surg 50:110-113

22. Lehman JA Jr, Hass AJ, Haas DG (1984) Surgical orthodontic correction of transverse maxillary deficiency: a simplified approach. Plast Reconstr Surg 73:62-68

23. Seeberger R, Kater W, Davids R, Thiele OC (2010) Long term effects of surgically assisted rapid maxillary expansion without performing osteotomy of the pterygoid plates. J Craniomaxillofac Surg 38:175-178. doi:10.1016/j.jcms.2009.07.003

24. Girotto JA, Davidson J, Wheatly M, et al. (1998) Blindness after reduction of facial fractures. Plast Reconstr Surg 102:1821-1834

25. Laningan DT, Hey JH, West RA (1990) Major vascular complications of orthognathic surgery: hemorrhage associated with Le Fort I osteotomies. J Oral Maxillofac Surg 48:561-573

26. Racey GL (1992) Discussion: surgically assisted rapid palatal expansion: an outpatient technique with long-term stability. J Oral Maxillofac Surg 50:114-115 